\title{
MDC1 directs chromosome-wide silencing of the sex chromosomes in male germ cells
}

\author{
Yosuke Ichijima, ${ }^{1,2}$ Misako Ichijima, ${ }^{1,2}$ Zhenkun Lou, ${ }^{3}$ André Nussenzweig, ${ }^{4}$ \\ R. Daniel Camerini-Otero, ${ }^{5}$ Junjie Chen, ${ }^{6}$ Paul R. Andreassen, ${ }^{2,7}$ and Satoshi H. Namekawa ${ }^{1,2,8}$ \\ ${ }^{1}$ Division of Reproductive Sciences, Perinatal Institute, Cincinnati Children's Hospital Medical Center, Cincinnati, Ohio 45229, \\ USA; ${ }^{2}$ Department of Pediatrics, University of Cincinnati College of Medicine, Cincinnati, Ohio 45229, USA; ${ }^{3}$ Division \\ of Oncology Research, Department of Oncology, Mayo Clinic, Rochester, Minnesota 55905, USA; ${ }^{4}$ Experimental Immunology \\ Branch, National Cancer Institute, National Institutes of Health, Bethesda, Maryland 20892, USA; ${ }^{5}$ Genetics and \\ Biochemistry Branch, National Institute of Diabetes and Digestive and Kidney Diseases (NIDDK), National Institutes of \\ Health, Bethesda, Maryland 20892, USA; ${ }^{6}$ Department of Experimental Radiation Oncology, University of Texas M.D. \\ Anderson Cancer Center, Houston, Texas 77030, USA; ${ }^{7}$ Division of Experimental Hematology and Cancer Biology, Cincinnati \\ Children's Hospital Medical Center, Cincinnati, Ohio 45229, USA
}

Chromosome-wide inactivation is an epigenetic signature of sex chromosomes. The mechanism by which the chromosome-wide domain is recognized and gene silencing is induced remains unclear. Here we identify an essential mechanism underlying the recognition of the chromosome-wide domain in the male germline. We show that mediator of DNA damage checkpoint 1 (MDC1), a binding partner of phosphorylated histone $\mathrm{H} 2 \mathrm{AX}(\gamma \mathrm{H} 2 \mathrm{AX})$, defines the chromosome-wide domain, initiates meiotic sex chromosome inactivation (MSCI), and leads to XY body formation. Importantly, MSCI consists of two genetically separable steps. The first step is the MDC1independent recognition of the unsynapsed axis by DNA damage response (DDR) factors such as ataxia telangiectasia and Rad3-related (ATR), TOPBP1, and $\gamma \mathrm{H} 2 \mathrm{AX}$. The second step is the MDC1-dependent chromosome-wide spreading of DDR factors to the entire chromatin. Furthermore, we demonstrate that, in somatic cells, MDC1-dependent amplification of the $\gamma \mathrm{H} 2 \mathrm{AX}$ signal occurs following replicative stress and is associated with transcriptional silencing. We propose that a common DDR pathway underlies both MSCI and the response of somatic cells to replicative stress. These results establish that the DDR pathway centered on MDC1 triggers epigenetic silencing of sex chromosomes in germ cells.

[Keywords: germ cells; meiosis; meiotic sex chromosome inactivation; DNA damage response; $\mathrm{MDC} 1 ; \gamma \mathrm{H} 2 \mathrm{AX}]$ Supplemental material is available for this article.

Received January 7, 2011; revised version accepted March 14, 2011.

Sex chromosomes are representative models of epigenetic gene regulation in which transcription is regulated in a chromosome-wide manner during development. In mammalian females, one of the $\mathrm{X}$ chromosomes is inactivated to equalize the $\mathrm{X}$-linked gene dosage between $\mathrm{XX}$ females and $\mathrm{XY}$ males. For female X-inactivation, placental mammals, including humans and mice, acquired a noncoding RNA (Xist) that decorates an entire $\mathrm{X}$ chromosome to initiate chromosome-wide gene silencing (Chow and Heard 2010; Lee 2010). Another form of $X$ inactivation occurs in male germ cells. During male meiosis, $\mathrm{X}$ and $\mathrm{Y}$ chromosomes are specifically silenced in a process called meiotic sex chromosome inactivation (MSCI). MSCI is an indispensable step in spermatogenesis. In contrast to female $\mathrm{X}$ in-

${ }^{8}$ Corresponding author.

E-MAIL satoshi.namekawa@cchmc.org; FAX (513) 803-1160.

Article is online at http://www.genesdev.org/cgi/doi/10.1101/gad.2030811. activation, male MSCI is known to be Xist-independent (McCarrey et al. 2002; Turner et al. 2002). Despite previous studies that have implicated DNA damage response (DDR) factors in MSCI (Turner 2007; Inagaki et al. 2010), it remains unclear how the sex chromosomes are recognized and how gene silencing occurs in a chromosome-wide manner in male germ cells.

Germ cells faithfully transmit life's identity to the next generation and confer genetic diversity. During meiosis, homologous chromosomes undergo synapsis and recombination, leading to genetically variable gametes. In contrast, heterologous chromatins (such as sex chromosomes) are epigenetically silenced during meiosis in various organisms-including the fungus Neurospora, Caenorhabditis elegans, Drosophila, birds, and mammals-although the underlying mechanisms depend on the species (Kelly and Aramayo 2007; Namekawa and Lee 2009). Meiotic silencing of unsynapsed chromatin (MSUC) is thought to 
be an ancient fundamental mechanism designed to suppress heterologous unsynapsed chromatin (Baarends et al. 2005; Turner et al. 2005). This trait may have evolved as a genome defense mechanism to protect the host genome from invasion by external DNA, such as transposons (Huynh and Lee 2005; Kelly and Aramayo 2007). In the mammalian male germline, meiotic silencing is confined to the $\mathrm{X}$ and $\mathrm{Y}$ chromosomes (which are heterologous and largely unsynapsed) and manifests as MSCI (McKee and Handel 1993; Turner 2007; Namekawa and Lee 2009; Yan and McCarrey 2009; Inagaki et al. 2010).

Cytological evidence suggests that various DDR factors accumulate at sites of heterologous $\mathrm{X}$ and $\mathrm{Y}$ chromosomes. First, ataxia telangiectasia and Rad3-related (ATR) kinase, TOPBP1 (an ATR activator), and BRCA1 accumulate on the unsynapsed axis of the sex chromosome (Scully et al. 1997; Moens et al. 1999; Perera et al. 2004; Reini et al. 2004; Turner et al. 2004). Second, phosphorylation of H2AX $(\gamma \mathrm{H} 2 \mathrm{AX})$ marks entire sex chromosomes at the onset of MSCI (Mahadevaiah et al. 2001). Previous studies suggest that, during MSCI, $\gamma \mathrm{H} 2 \mathrm{AX}$ occurs independently of ataxia telangiectasia-mutated (ATM) kinase but is dependent on ATR kinase (Turner et al. 2004; Bellani et al. 2005). ATR is known to sense ssDNA at the site of DNA damage in somatic cells (Cimprich and Cortez 2008; Friedel et al. 2009). H2AX knockout mice cannot induce MSCI and meiotic progression is arrested, suggesting the importance of H2AX in MSCI (Fernandez-Capetillo et al. 2003). However, genetic evidence is lacking to ascertain whether phosphorylation of $\mathrm{H} 2 \mathrm{AX}$ and the associated DDR pathway are essential for MSCI.

To uncover the molecular mechanism underlying MSCI, we focused attention on mediator of DNA damage checkpoint 1 (MDC1), a binding partner of $\gamma \mathrm{H} 2 \mathrm{AX}$. MDC1 plays a crucial role in the DDR signaling pathway downstream from $\gamma \mathrm{H} 2 \mathrm{AX}$ in somatic cells (Goldberg et al. 2003; Lou et al. 2003; Stewart et al. 2003). In this study, we show that MDC1 is an essential factor for the recognition of the chromosome-wide domain of meiotic sex chromosomes in male mice, and MDC1 is therefore indispensable in the establishment of MSCI and the XY body. Importantly, our studies in Mdc1 knockout mice reveal that MSCI is genetically separable into two steps: MDC1-independent chromosome axis recognition and MDC1-dependent chromosome-wide domain formation. Herein we identify a novel mechanism of chromosome-wide regulation based on cisrecognition. Furthermore, the DDR pathway has a shared role in both MSCI and the somatic response to replicative stress during $S$ phase. These results establish that the DDR pathway, centered on MDC1, recognizes chromosome-wide domains and induces epigenetic silencing of sex chromosomes in germ cells.

\section{Results}

MDC1 is essential for chromosome-wide spreading of $\gamma H 2 A X$

To test the role of MDC1 in MSCI, we examined the phenotype of $M d c 1^{-/-}$mice in male spermatogenesis. A previous study revealed male-specific infertility in $M d c 1^{-/-}$ mice due to meiotic arrest, whereas $M d c 1^{-/-}$females are fertile, suggesting a critical role for $\mathrm{MDC1}$ in a malespecific event in meiosis (Lou et al. 2006). A subsequent study confirmed that spermatogenesis in $M d c 1^{-/-}$mice is arrested at epithelial stage IV, which corresponds to the mid-pachytene stage in normal meiosis (Ahmed et al. 2007). Consistent with previous studies, we did not observe abnormalities in $M d c 1^{-/-}$mice before entry into meiosis (Supplemental Fig. S1) and spermatids were not observed in $M d c 1^{-1-}$ males, indicating that $\mathrm{MDCl}$ is indispensable in male meiosis.

To further investigate the role of MDC1 in meiosis, we examined meiotic chromosome spreads of $M d c 1^{-1-}$ mice. In the leptotene and zygotene stages, when homologous chromosomes undergo synapsis following meiosis-specific DNA double-strand breaks (DSBs), the first wave of $\gamma \mathrm{H} 2 \mathrm{AX}$ accumulation occurred extensively in $\mathrm{Mdc1}^{-/-}$ nuclei, as in the control (Supplemental Fig. S2). After the early pachytene stage in normal meiosis, when homologous synapsis is completed, $\gamma \mathrm{H} 2 \mathrm{AX}$ localized on the chromosome-wide domain of the sex chromosomes (Fig. 1A). However, in $M d c 1^{-/-}$spermatocytes, chromosomewide accumulation of $\gamma \mathrm{H} 2 \mathrm{AX}$ on sex chromosomes was significantly impaired at the pachytene stage, and the $\gamma \mathrm{H} 2 \mathrm{AX}$ signal was confined to the unsynapsed axis and proximal regions of sex chromosomes (Fig. 1B). This phenotype was observed in all $M d c 1^{-/-}$pachytene spermatocytes that we examined, and spermatid progression to later stages totally failed $(n>100)$, indicating that sex chromosome-wide accumulation of $\gamma \mathrm{H} 2 \mathrm{AX}$ is a critical step in meiotic progression. However, it is also possible that the $\gamma \mathrm{H} 2 \mathrm{AX}$-spreading defect in $\mathrm{Mdc1}^{-/-}$spermatocytes is caused indirectly by meiotic arrest during the course of $\gamma \mathrm{H} 2 \mathrm{AX}$ spreading. To test this possibility, we examined meiotic progression by staining a testis-specific histone variant $(\mathrm{H} 1 \mathrm{t})$ that specifically accumulates after the mid-pachytene stage, when MSCI is already established in normal meiosis (Inselman et al. 2003). We confirmed that $\mathrm{Mdc1}^{-/-}$germ cells can reach the H1tpositive stage, correlating with the mid-pachytene stage. Since the spreading defect is evident in H1t-positive cells (Supplemental Fig. S1), our results suggest that this defect is not the indirect consequence of meiotic arrest. Thus, we conclude that MDC1 is an essential factor for spreading $\gamma \mathrm{H} 2 \mathrm{AX}$ from the axes to the chromosome-wide domain of sex chromosomes in the pachytene stage.

Next, we examined the localization of ATR and TOPBP1 (ATR activator), which are thought to form a protein complex and be involved in phosphorylation of H2AX during MSCI (Turner et al. 2004; Bellani et al. 2005). In normal meiosis, during the zygotene-to-pachytene transition, ATR and TOPBP1 initially accumulated on the unsynapsed axes of sex chromosomes and then spread onto the chromosome-wide domain of the sex chromosomes (Fig. $1 \mathrm{C}, \mathrm{E})$. Intriguingly, in $M d c 1^{-/-}$spermatocytes, the spreading of ATR and TOPBP1 from the unsynapsed axes to the chromosome-wide domain of the sex chromosomes was not observed, and the signals existed only on the unsynapsed axes (Fig. 1D,F). These results suggest that MDC1 is 

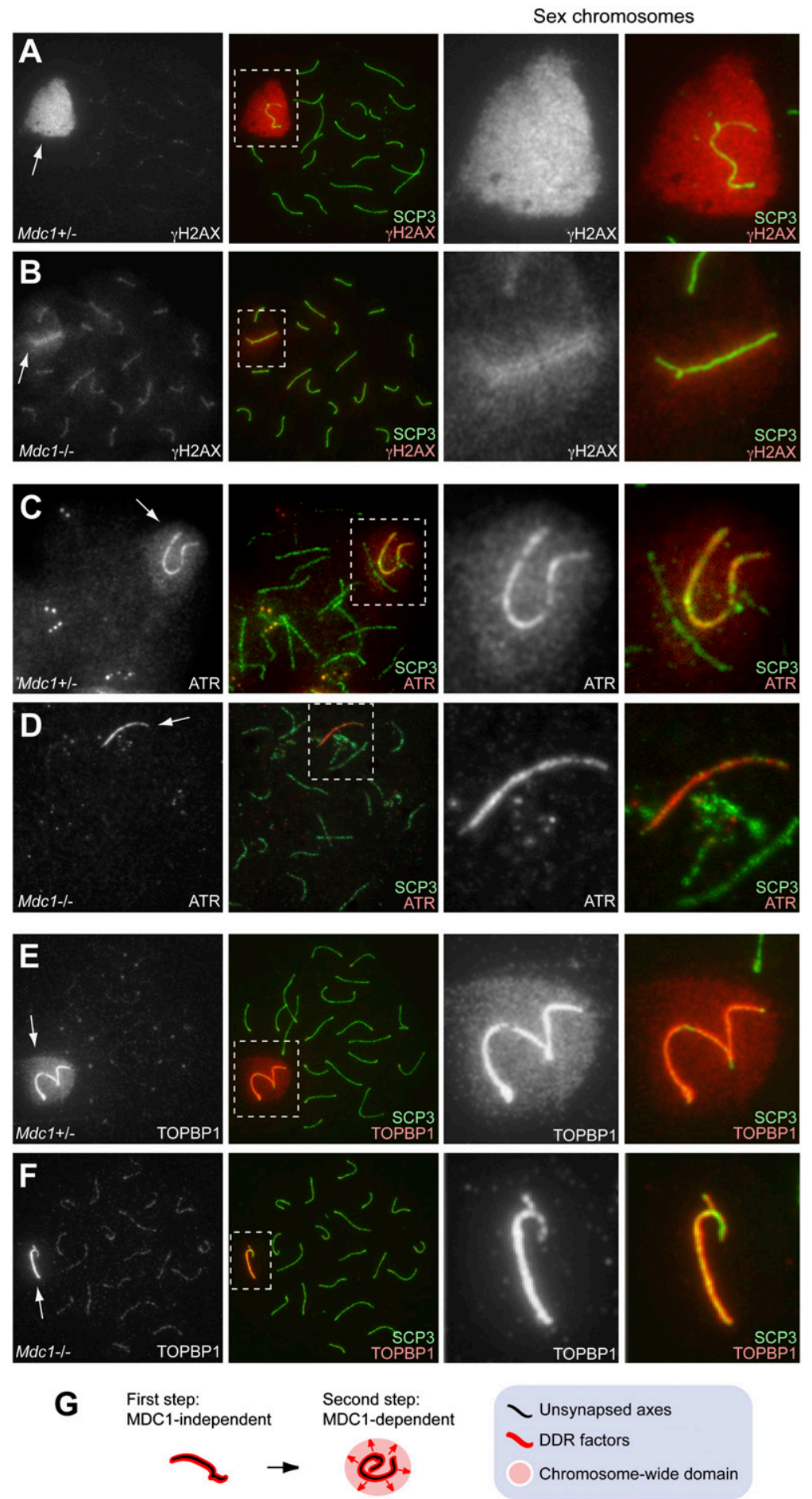

Figure 1. MDC1 directs chromosome-wide spreading of DDR factors. $(A-F)$ Immunostaining of meiotic chromosome spreads using antibodies against DDR factors together with the anti-SCP3 antibody. SCP3 staining displays the status of chromosome synapsis and is used to distinguish meiotic stages. All images are wide-field images of pachytene spermatocytes. Areas surrounding sex chromosomes are highlighted in dotted rectangles and are magnified in the right panels. (Arrows) Sex chromosomes. $(G)$ Pictorial representation about the role of $\mathrm{MDCl}$ in MSCI. The first step is MDC1-independent recognition of the unsynapsed axis. The second step is MDC1-dependent spreading of DDR factors to the chromosome-wide domain. an essential factor needed to build up chromosome-wide spreading of ATR and TOPBP1, as well as $\gamma \mathrm{H} 2 \mathrm{AX}$. On the contrary, localization of BRCA1 was not altered in $M d c 1^{-/-}$spermatocytes and was confined to the unsynapsed axes of sex chromosomes, as in controls (Supplemental Fig. S3). This suggests that BRCA1 does not function downstream from MDC1 during MSCI. Supporting its role in chromosome-wide spreading of DDR factors, MDC1 spreads onto the chromosome-wide domain in normal pachytene spermatocytes (Supplemental Fig. S3; Lee et al. 2005). Taken together, we conclude that MSCI consists of two genetically separable steps. The first step is the MDC1-independent recognition of the unsynapsed axis, in which the ATR-TOPBP1 complex phosphorylates H2AX (Fig. 1G). The second step is the MDC1-dependent chromosome-wide spreading of 
the ATR-TOPBP1 complex and the $\gamma \mathrm{H} 2 \mathrm{AX}$ signal to the entire chromatin (Fig. 1G).

In addition to these factors, various DDR factors are known to accumulate on the sex chromosomes at the onset of MSCI. Mre11, Rad50, and Nbs1 form the multimeric MRN complex and accumulate at sites of DNA DSBs in somatic cells following $\gamma \mathrm{H} 2 \mathrm{AX}$ foci formation (Furuta et al. 2003). The MRN complex also accumulates on the chromosome-wide domain of the sex chromosomes during MSCI (Supplemental Fig. S4; Eijpe et al. 2000). To dissect the genetic pathway that $\mathrm{MDC} 1$ is involved in, we examined the localization of the MRN complex in $M d c 1^{-/-}$spermatocytes. Mre11 and Rad50 localized on the unsynapsed axes of sex chromosomes in $M d c 1^{-/}$spermatocytes (Supplemental Fig. S4). This indicates that recruitment of the MRN complex to the unsynapsed axes is MDC1-independent, but that $\mathrm{MDC1}$ is required for spreading of the MRN complex to the sex chromosome-wide domain. Although the function of the MRN complex in MSCI is unknown, these results further corroborate the essential role of MDC1 in the recognition of the chromosome-wide domain of the sex chromosomes by DDR factors during MSCI.

\section{MDC1 initiates MSCI}

To determine whether MDC1-dependent chromosomewide recognition is needed for transcriptional silencing of the sex chromosomes, we examined the general transcriptional status by immunostaining using an antibody against RNA polymerase II (Pol II). We prepared meiotic slides using a method we developed previously to conserve the morphology of meiotic chromatin and the threedimensional nuclear structure (Namekawa et al. 2006; Namekawa and Lee 2011). In normal pachynema, the sex chromosomes formed a silent compartment, called the XY body, in which Pol II was largely excluded from the entire sex chromosome (Fig. 2A,C; Namekawa et al. 2006). In $M d c 1^{-/-}$pachynema, the unsynapsed axes of sex chromosomes were located largely in the transcriptionally active euchromatic region, except for the centromeric end of the $\mathrm{X}$ chromosome and a large part of the $\mathrm{Y}$ chromosome that is known to reside in silent heterochromatin even before meiosis (Fig. 2B,D; Namekawa et al. 2006). We conclude that $\mathrm{MDC1}$ is required for establishing chromosome-wide silencing. This conclusion was confirmed independently by Cot-1 RNA fluorescent in situ hybridization (FISH). Cot-1 DNA consists of repetitive elements that can hybridize to nascent transcripts, leading to visible transcriptionally active regions (Hall et al. 2002). The Cot-1 signal was similarly excluded from the XY in the control, as was the case for Pol II staining (Fig. 2E). In contrast, the unsynapsed axes of sex chromosomes were located in the Cot-1-positive region in $M d c 1^{-/-}$spermatocytes (Fig. 2F) despite the fact that various DDR factors accumulated on
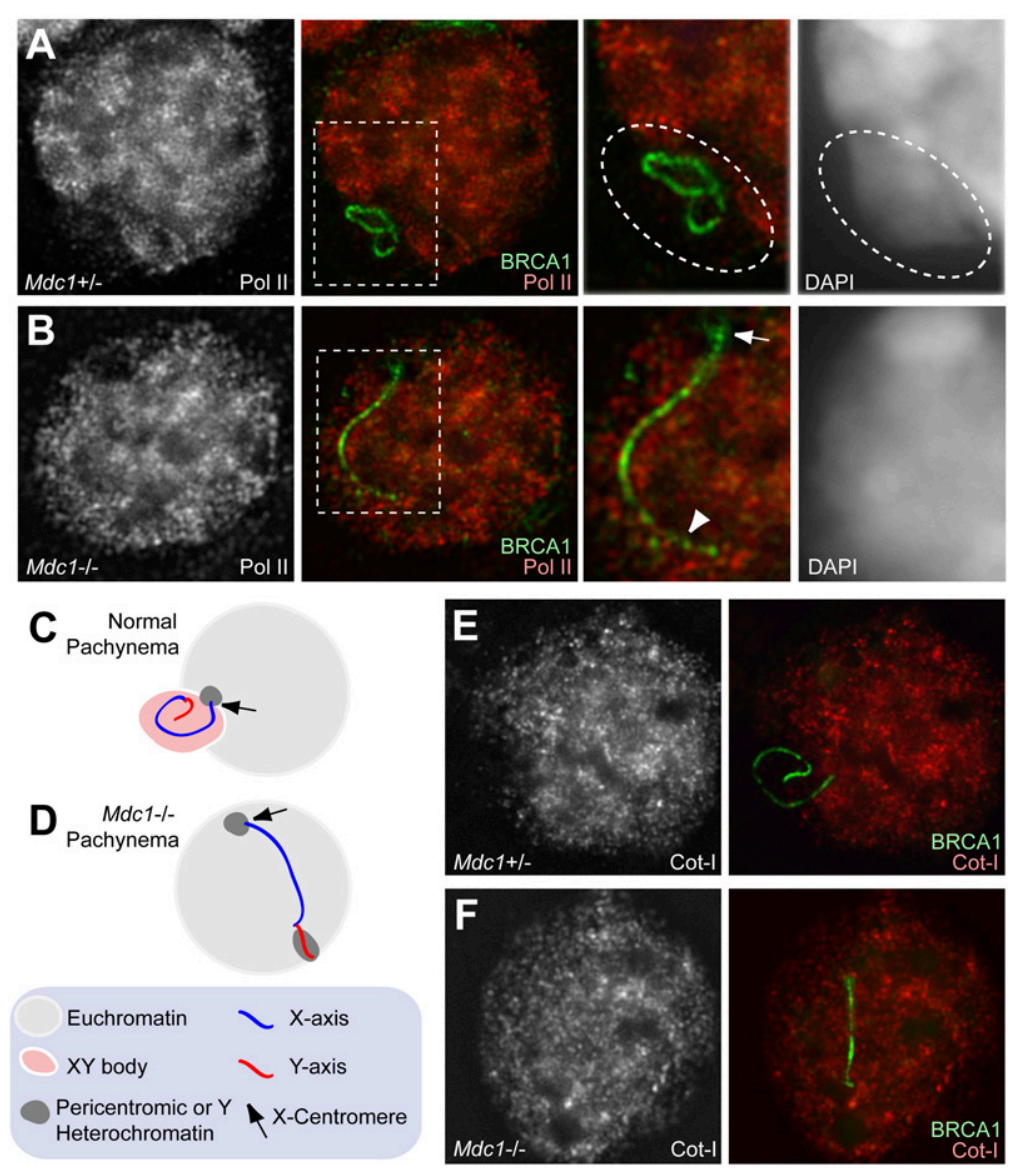

Figure 2. MDC1 is required for MSCI. $(A, B)$ Immunostaining with anti-Pol II antibody in $M d c 1^{+-}$and $M d c 1^{-/-}$spermatocytes, respectively. Unsynapsed axes of sex chromosomes are detected with antiBRCA1 antibody. Areas surrounding sex chromosomes are highlighted in dotted rectangles and are magnified in the right panels. The outline of the $\mathrm{XY}$ body is highlighted with a dotted oval. (Arrow) Centromeric end of the $\mathrm{X}$ chromosome; (arrowhead) Y-chromosome part of the sex chromosome pair. $(C, D)$ Pictorial representation of the unsynapsed axes of sex chromosomes. $(E, F)$ Combined immunostaining with anti-BRCA1 antibody and Cot-1 RNA FISH in $M d c 1^{+/-}$ and $M d c 1^{-1-}$ cells, respectively. Meiotic slides were prepared as described (Namekawa et al. 2006). All images are deconvolved single $Z$-sections. 
the axes (Fig. 1). This suggests that the chromatin conformational change following DDR factor accumulation is required for transcriptional silencing.

To confirm these cytological analyses, we performed microarray analysis using Affymetrix Gene 1.0 ST arrays to examine gene expression profiles in juvenile testes in which the first wave of meiosis is semisynchronous. For example, the pachytene stage commences at $\sim 10 \mathrm{~d}$ after birth. At $16.5 \mathrm{~d}$ old, when MSCI is already established in normal meiosis, genes on the sex chromosomes were not repressed and were consequently up-regulated in $M d c 1^{-/-}$ testes as compared with wild-type testes (Fig. 3A). We also examined average expression levels in individual chromosomes and confirmed that up-regulation in $M d c 1^{-1-}$ testes is specific to the sex chromosomes (Fig. 3B). Up-regulation of the $\mathrm{X}$ chromosome in $\mathrm{Mdc1^{-/- }}$ testes occurs in a chromosome-wide manner (Fig. 3C). We conclude that MDC1dependent recognition of the chromosome-wide domain is a critical step in the initiation of chromosome-wide silencing in MSCI.

\section{MDC1 is required for XY body formation}

The chromosome-wide accumulation of $\gamma \mathrm{H} 2 \mathrm{AX}$ on sex chromosomes is concomitant with the formation of a distinct heterochromatin domain called the XY body (also known as sex body). Various epigenetic modifications, including histone modifications, occur specifically on the XY body following its formation /Greaves et al. 2006; Namekawa et al. 2006; Turner et al. 2006; van der Heijden et al. 2007). The XY body is a distinct chromatin domain detected by characteristic DAPI staining, as shown in Figure 2A. The MSCI defect in $M d c 1^{-1-}$ spermatocytes suggests that MDC1 is essential for the formation of this distinct chromatin domain. To determine whether XY body formation depends on MDC1, we examined localization of various XY body markers. Sumoylation occurs on entire sex chromosomes in normal meiosis (Fig. 4A; Rogers et al. 2004), but was completely abolished in $M d c 1^{-/-}$spermatocytes (Fig. 4B). Although a previous observation suggested that SUMO-1 accumulation precedes $\gamma \mathrm{H} 2 \mathrm{AX}$ on the XY body (Vigodner 2009), our genetic evidence demonstrates unequivocally that $\gamma \mathrm{H} 2 \mathrm{AX}-\mathrm{MDC} 1$ signaling is upstream of SUMO-1 accumulation in both the axes and the chromosome-wide domain of the sex chromosomes. Consistent with this result, a recent study revealed that SUMO proteins function downstream from the DDR pathway in somatic cells (Galanty et al. 2009). Furthermore, various XY body markers-such as Xmr (Escalier and Garchon 2000), MacroH2A1 (Hoyer-Fender et al. 2000), ubiquitin conjugates (FK2), and ubiquitinated histone $\mathrm{H} 2 \mathrm{~A}$ (Ubi-H2A) (Baarends et al. 2005)-did not localize on chromosome-wide domains on the sex chromosome in $M d c 1^{-1-}$ cells (Fig. 4C-J). Axial accumulation of $\mathrm{Xmr}$, $\mathrm{MacroH} 2 \mathrm{~A}$, and Ubi-H2A was observed in $M d c 1^{-/-}$cells, however. Exclusion of histone H3 trimethylated at Lys 27 (H3K27me3) was also MDC1-dependent (Fig. 4K,L). Taken together, we establish that $\gamma \mathrm{H} 2 \mathrm{AX}-\mathrm{MDC} 1$ signaling precedes chromosome-wide accumulation of various XY body markers and confers chromosome-wide epigenetic alterations on the sex chromosomes.

We further investigated the chromatin conformation of sex chromosomes by directly measuring the degree of compaction of the XY chromosome axes. For this purpose, we quantified the distance between the distal ends of the XY axes displayed by BRCA1 staining (Fig. 4M,N). As illustrated in Figure 4M, sex chromosome axes in $M d c 1^{-1-}$ pachynema were stretched longer than those in normal spermatocytes in both early and mid-pachytene stages (Fig. 4N). These results demonstrate that $\mathrm{MDC} 1$ directs the chromatin conformational change of sex chromosomes at the early pachytene stage, concomitant with the establishment of MSCI, leading to establishment of the XY body.

\section{Meiotic recombination in $\mathrm{Mdc1}^{-/-}$mice}

DDR factors, including $\gamma \mathrm{H} 2 \mathrm{AX}$ and MDC1, also accumulate in autosome regions at the leptotene and zygotene stages (Mahadevaiah et al. 2001; Lee et al. 2005) when meiosis-specific DSBs are induced by Spol1 to initiate

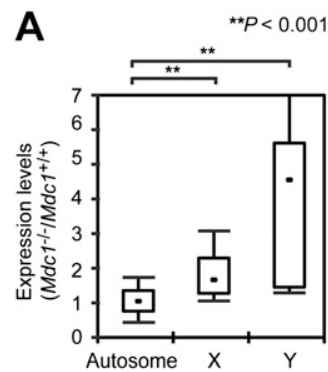

B

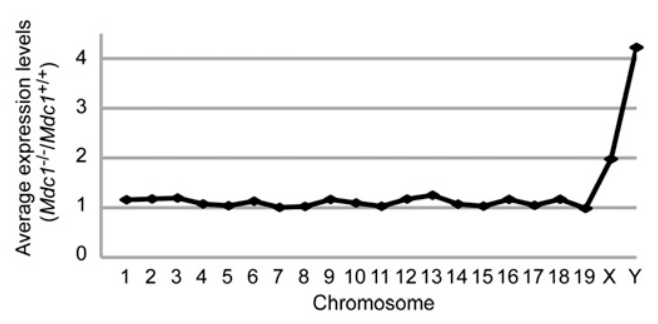

C
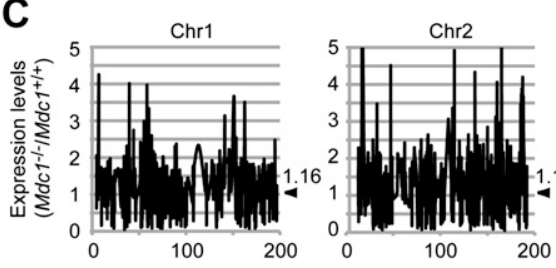
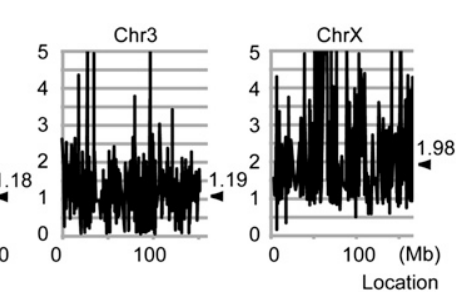

Figure 3. Microarray analysis of $M d c 1^{-/}$testis at $16.5 \mathrm{~d}$ old. (A) Comparison of gene expression levels in $M d c 1^{-/-}$versus $M d c 1^{+/+}$cells among autosomes or $\mathrm{X}$ and $\mathrm{Y}$ chromosomes. The central dot is the median, the boxes encompass $50 \%$ of data points, and the error bars indicate $90 \%$ of data points. $P$ was derived from a paired $t$-test. $(B)$ Average expression levels in $M d c 1^{-/-}$versus $M d c 1^{+/+}$mice for each chromosome. $(C)$ Expression levels along the location of representative autosomes (Chrl-Chr3) and the $\mathrm{X}$ chromosome. Locations are distances from proximal ends of chromosomes (in megabases). Arrowheads denote average expression levels in each chromosome. 

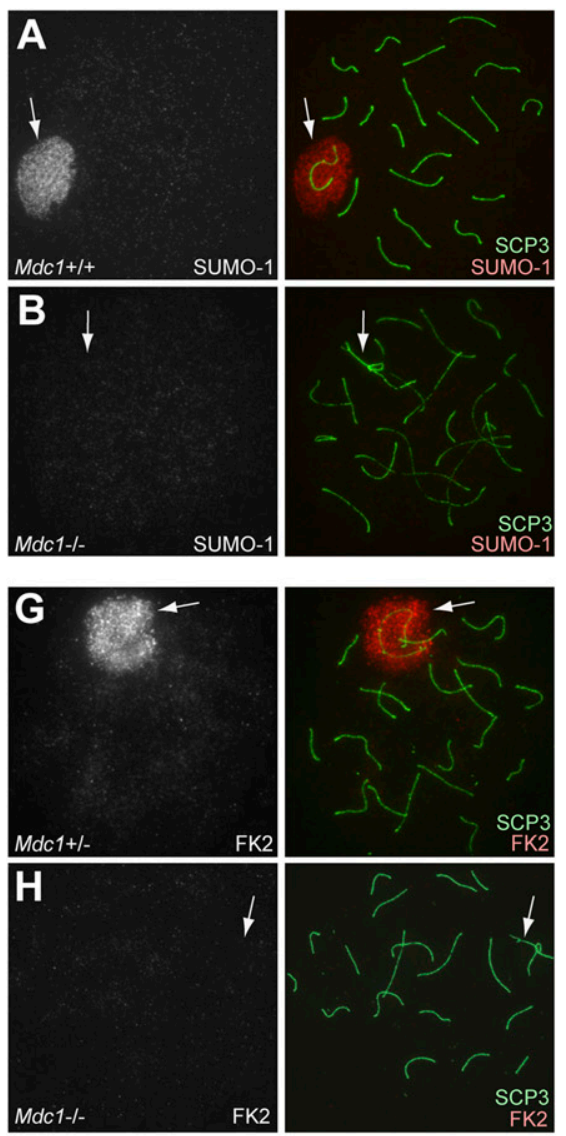

M
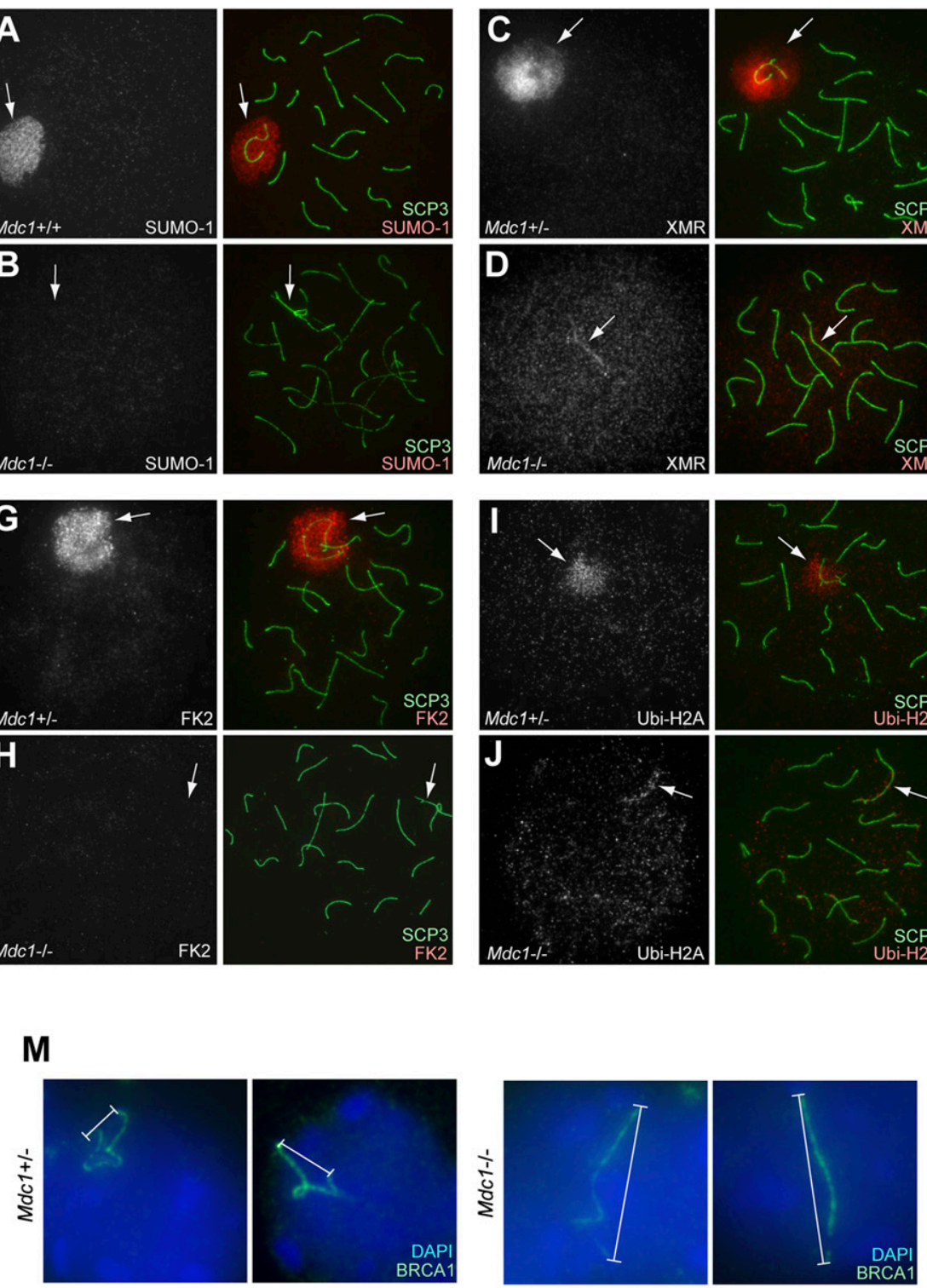
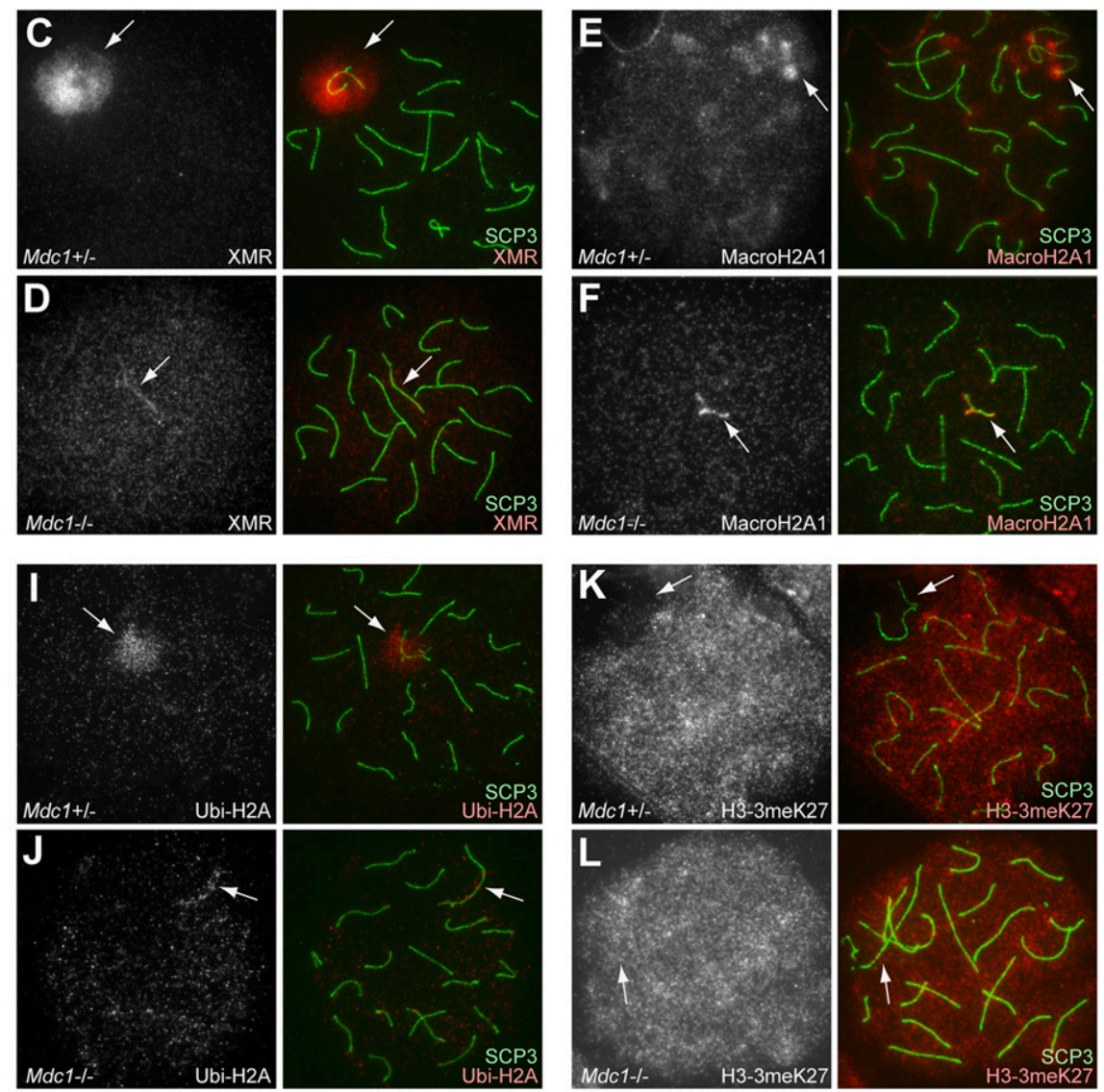

$\mathbf{N}$

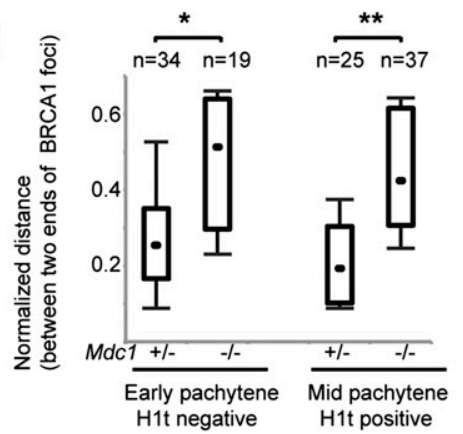

Figure 4. $\quad \gamma \mathrm{H} 2 \mathrm{AX}-\mathrm{MDC} 1$ signaling is the primary step in $\mathrm{XY}$ body formation. $(A-L)$ Immunostaining of meiotic chromosome spreads using the indicated antibodies together with the anti-SCP3 antibody. All pictures represent pachytene spermatocytes. (Arrows) Sex chromosomes. All images are wide-field images. $(M)$ Conformation of sex chromosome axes detected by BRCA1 staining in pachytene $M d c 1^{+/-}$and $M d c 1^{-1-}$ spermatocytes. To preserve relative three-dimensional conformation, meiotic slides were prepared as described (Namekawa et al. 2006). (N) Summary of linear distances between both ends of sex chromosome axes. The normalized distance is the linear distance between both ends detected with BRCAl staining normalized to the nuclear diameter. The central dot is the median, the boxes encompass $50 \%$ of data points, and the error bars indicate $90 \%$ of data points. Meiotic stages were judged by simultaneous staining with SCP3 and H1t. $P$-values were calculated using an unpaired $t$-test. $\left.\left({ }^{\star}\right) P<0.01 ;{ }^{\star \star}\right) P<0.001$.

meiotic recombination (Baudat et al. 2000; Romanienko and Camerini-Otero 2000). This meiotic recombination is tightly associated with the progression of homologous chromosome synapsis. Intriguingly, $\gamma \mathrm{H} 2 \mathrm{AX}$ and TOPBP1 foci remained along autosome axes in $M d c 1^{-/-}$pachytene spermatocytes, but decreased on autosome axes in normal meiosis (Fig. 1). If MDC1 has a role in processing meiotic DSBs at the leptotene and zygotene stages, it could in- directly disturb meiotic silencing at the subsequent pachytene stage in $M d c 1^{-/-}$mice. To distinguish the roles of MDC1 in meiotic silencing and recombination, we characterized the roles of $\mathrm{MDC} 1$ in meiotic recombination using $M d c 1^{-1-}$ mice. We first examined chromosome synapsis, which is tightly associated with the initiation of meiotic recombination in mice (Baudat et al. 2000; Romanienko and Camerini-Otero 2000). We found normal 
synapsis of $M d c 1^{-/-}$autosomes at the pachytene stage $(n=$ 70 ), as judged by immunostaining of SCP1, which localizes only on synapsed chromosomes (Fig. 5A,B). This suggests that $\mathrm{MDC} 1$ is not required for the initial stage of meiotic recombination. However, $M d c 1^{-/-}$spermatocytes exhibited sex chromosome-specific synaptic defects, $\mathrm{X}$ and $\mathrm{Y}$ axes that were not associated (14\%, $n=70)$ (Fig. 5C), and illegitimate association of an end of the X axis to autosomes $(24 \%$,
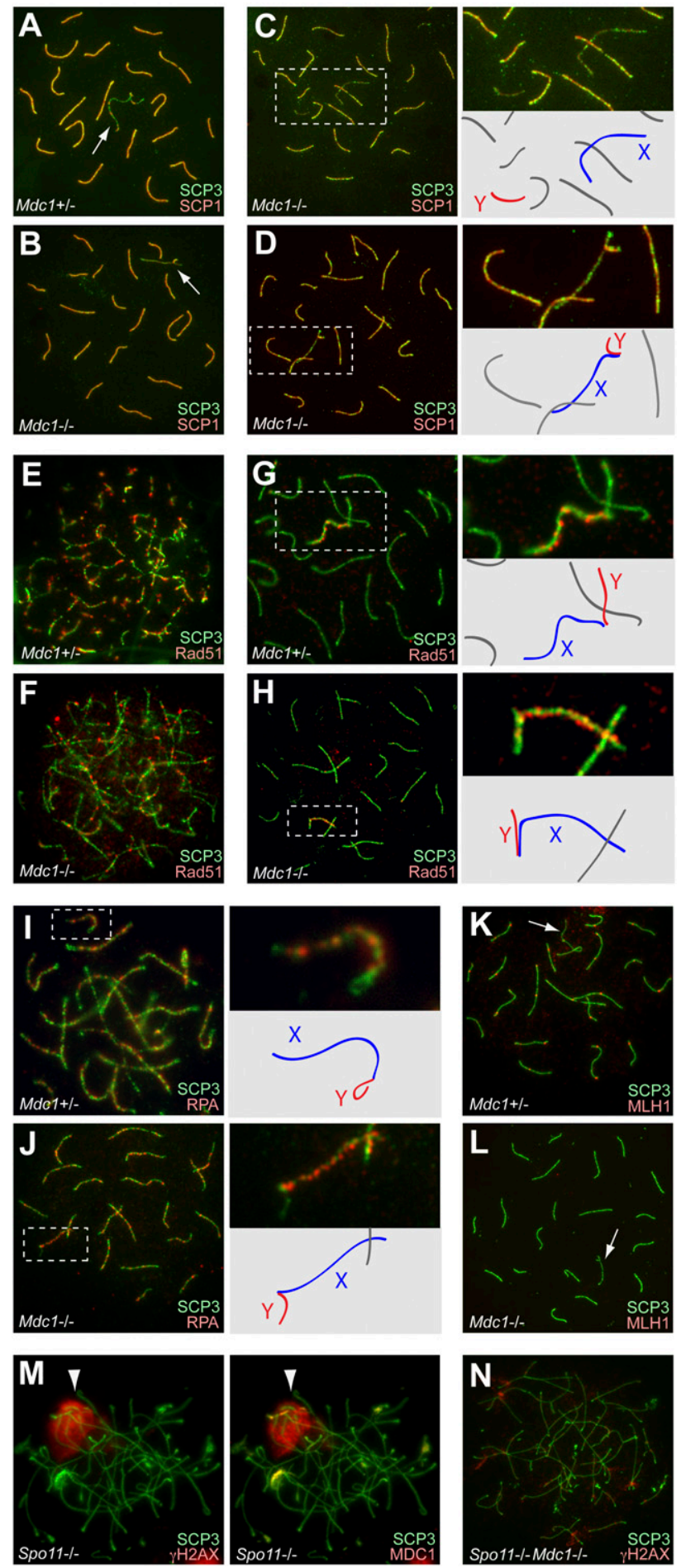

$n=70$ ) (Fig. 5D) at a higher frequency than in normal spermatocytes (both $0 \%, n=50$ ). These abnormalities are also observed in H2AX knockout mice (Celeste et al. 2002; Fernandez-Capetillo et al. 2003), suggesting the crucial role of $\gamma \mathrm{H} 2 \mathrm{AX}-\mathrm{MDC} 1$ signaling in sex chromosome synapsis.

To examine the phenotype in terms of processing meiotic DSBs in $M d c 1^{-/-}$spermatocytes, we examined the localization of recombination intermediates by immunofluorescence with marker antibodies such as RAD51, RPA, and MLH1 (Plug et al. 1998; Tarsounas et al. 1999). RAD51 accumulated at sites of DSBs and subsequent strand invasion during meiotic recombination in the leptotene and zygotene stages in controls (Fig. 5E). After processing of recombination intermediates at the pachytene stage, RAD51 disappeared from autosomal axes and remained only on the X axis (Fig. 5G; Plug et al. 1998). In $M d c 1^{-/-}$ spermatocytes, localization of RAD51 foci was indistinguishable from that in normal spermatocytes (Fig. 5F,H). Next we examined the localization of RPA, an ssDNAbinding protein that marks synapsed regions at the site of recombination after the zygotene stage. RPA is a late marker of recombination intermediates, after RAD51 accumulation (Fig. 5I; Plug et al. 1998). In $M d c 1^{-/-}$spermatocytes, RPA foci formation occurred normally, suggesting normal processing of meiotic DSBs (Fig. 5J). However, the localization of MLH1, which marks one or two sites of crossover recombination in normal meiosis (Fig. 5K; Baker et al. 1996), was completely abolished in $M d c 1^{-1-}$ spermatocytes (Fig. 5L). These results in $M d c 1^{-1-}$ spermatocytes raised two possibilities: that $\mathrm{MDC} 1$ has a direct role in processing crossover recombination and promoting MLH1 accumulation, or that an MSCI defect causes meiotic arrest at the stage before MLH1 accumulation and indirectly impedes MLH1 accumulation on autosomes.

To address these two possibilities, we examined the recombination intermediates in $M d c 1^{-1-}$ female meiosis. Consistent with normal fertility in female $M d c 1^{-/-}$mice, we observed normal accumulations of RPA and MLH1

Figure 5. Meiotic recombination in the $M d c 1$ mutant. Immunostaining of meiotic chromosome spreads using the indicated antibodies together with the anti-SCP3 antibody. All images are wide-field images. (Arrows) Sex chromosomes. $(A, B)$ Chromosome synapsis occurs normally at the pachytene stage in $M d c 1^{+/-}$ and $M d c 1^{-/-}$spermatocytes. (C) $M d c 1^{-/-}$spermatocytes exhibit sex chromosome-specific synaptic defects. $(D)$ Illegitimate associations of the $\mathrm{X}$ axis to autosomes in $M d c 1^{-/-}$spermatocytes. Areas surrounding sex chromosomes (dotted rectangle) are magnified in the right panels, and schematics of chromosome axes are shown below. $(E, F)$ Rad51 foci formation is normal at the zygotene stage in $\mathrm{Mdc1}^{+-}$and $M d c 1^{-/-}$spermatocytes. $(G, H)$ Rad51 foci disappear from autosomal regions and remain only on the X-chromosome axis at the pachytene stage in $\mathrm{Mdc1}^{+/-}$and $M d c 1^{-/-}$spermatocytes. $(I, J)$ RPA foci formation is normal at the pachytene stage in $M d c 1^{+/-}$and $M d c 1^{-/-}$spermatocytes. (K) MLH1 marks the sites of crossover at the pachytene stage in $M d c 1^{+/-}$spermatocytes. (L) MLH1 foci are abolished in $M d c 1^{-/-}$ at the pachytene stage. $(M) \mathrm{MDC} 1$ localizes on the pseudo sex body in Spo11 $11^{-1-}$ spermatocytes. (Arrowhead) Pseudo sex body. $(N)$ The pseudo sex body is abolished in spermatocytes of the Spo11 ${ }^{-/-} M d c 1^{-/-}$double mutant. 
foci in $M d c 1^{-/-}$females (Supplemental Fig. S5). These results support the latter possibility that an MSCI defect causes meiotic arrest and indirectly abolishes MLH1 foci in $M d c 1^{-/-}$spermatocytes.

\section{A role for $M D C 1$ in meiotic silencing independent of meiotic recombination}

As further support for MDC1 function in meiotic silencing independent of meiotic recombination, we examined the Spo11 mutant $\left(\operatorname{Spo}_{\left.11^{-/}\right)}\right)$that is defective in inducing meiosis-specific DSBs and exhibits aberrant synapsis and meiotic arrest. Interestingly, meiotic silencing characterized by the accumulation of DDR factors such as ATR and $\gamma \mathrm{H} 2 \mathrm{AX}$ still takes place in Spo11 ${ }^{-/-}$spermatocytes. However, in this case, the region of meiotic silencing locates ectopically, rather than on sex chromosomes, presumably due to the aberrant synapsis of autosomes. This region is called the pseudo sex body (Barchi et al. 2005; Bellani et al. 2005; Mahadevaiah et al. 2008). These observations strongly suggest that meiotic silencing is a genetically separable event from meiosis-specific DSBs, although correct localization of silencing on sex chromosomes may be a consequence of homologous chromosome synapsis that is, in turn, strictly dependent on meiosis-specific DSBs. We found that MDC1 accumulated in the pseudo sex body in Spo11 $1^{-/}$spermatocytes and perfectly overlapped with $\gamma \mathrm{H} 2 \mathrm{AX}$, which illuminates the pseudo sex body domain (Fig. 5M). Furthermore, pseudo sex body formation was abolished in spermatocytes of the the $S p o 11^{-/} M d c 1^{-/-}$ double mutant (Fig. 5N). We conclude that MDC1 is required for pseudo sex body formation and meiotic silencing, supporting the notion that MDC1 functions directly in meiotic silencing independently of meiotic recombination.

\section{MDC1 functions independently of RNF8 in MSCI}

Next we sought to determine the pathway associated with MDC1 in MSCI. In the somatic DDR pathway, MDC1 recruits an E3 ubiquitin ligase, ring finger protein 8 (RNF8), via a direct interaction, leading to the subsequent recruitment of various DDR factors to the site of DNA damage (Huen et al. 2007; Kolas et al. 2007; Mailand et al. 2007). We found that RNF8 also localized on the XY body, but that the accumulation of RNF8 occurred only after the late diplotene phase (Supplemental Fig. S6). This is much later than that of $\mathrm{MDC1}$, suggesting that MDC1 and RNF8 operate independently in MSCI. To determine the role of RNF8 on the XY body, we examined the phenotype of $R n f 8^{-/-}$spermatocytes. In Rnf8 ${ }^{-/-}$spermatocytes, chromosome-wide accumulation of MDC1, TOPBP1, SUMO-1, and Xmr were not disturbed (Supplemental Fig. S6). This result is consistent with recent studies showing normal chromosome-wide accumulation of $\gamma \mathrm{H} 2 \mathrm{AX}$ on the sex chromosomes, while ubiquitin conjugates are abolished from the XY body in Rnf8 ${ }^{-/-}$spermatocytes (Lu et al. 2010; Santos et al. 2010). We conclude that RNF8 is dispensable for sex chromosome-wide localization of DDR factors and accumulation of XY body markers (except for ubiquitin conjugates), and MDC1 functions independently of RNF8 in MSCI.
A common role for MDC1 in meiotic silencing and the $D D R$ pathway after replicative stress in somatic cells

The above results establish that MDC1 works downstream from ATR and amplifies $\gamma \mathrm{H} 2 \mathrm{AX}$ signals in the chromosome-wide domain, which induces MSCI. Based on this conclusion, we hypothesized that a common DDR pathway underlies both meiotic silencing and the somatic $\mathrm{DDR}$, and that MDC1 is a common central player in $\gamma \mathrm{H} 2 \mathrm{AX}$ amplification. We anticipated that transcriptional silencing is a common consequence of $\gamma \mathrm{H} 2 \mathrm{AX}$ amplification in both meiotic silencing and somatic DDR. Supporting our notion, it has been shown that MDC1 amplifies $\gamma \mathrm{H} 2 \mathrm{AX}$ signals at the site of DNA DSBs in somatic cells by a feedback loop with ATM kinase (Lou et al. 2006). However, it is unclear whether MDC1-dependent $\gamma \mathrm{H} 2 \mathrm{AX}$ amplification also occurs downstream from ATR signaling. In somatic DDR, replicative stress activates an ATR-dependent pathway, rather than ATM, at the site of the stalled replication fork in S phase /Cimprich and Cortez 2008; Friedel et al. 2009). To explore our hypothesis, we investigated the role of MDCl in the ATR-dependent pathway after the induction of replicative stress in the U2OS human osteosarcoma cell line. We sought to determine whether MDC1 amplifies $\gamma \mathrm{H} 2 \mathrm{AX}$ signals after induction of replicative stress, and whether $\gamma \mathrm{H} 2 \mathrm{AX}$ foci are associated with transcriptional silencing, as is the case with meiotic silencing.

Replicative stress can be induced by treatment of cells with hydroxyurea (HU). We confirmed that HU treatment specifically induces $\gamma \mathrm{H} 2 \mathrm{AX}$ foci in $\mathrm{S}$ phase using 5-ethynyl-2'-deoxyuridine (EdU), which is incorporated into replicating cells (Fig. 6A). To determine the role of MDC1 in the ATR-dependent pathway, we performed siRNA-based knockdown of MDC1. Following MDC1 knockdown, we observed that $\gamma \mathrm{H} 2 \mathrm{AX}$ amplification was significantly hampered after $\mathrm{HU}$ treatment (Fig. 6B,C). We conclude that MDC1 is also necessary for $\gamma \mathrm{H} 2 \mathrm{AX}$ amplification in an ATR-dependent pathway of somatic cells. Therefore, we propose that MDC1 directs $\gamma \mathrm{H} 2 \mathrm{AX}$ amplification, possibly by a feedback loop with the ATRTOPBP1 complex, in both meiotic silencing and the response of somatic cells to replicative stress (Fig. 6D).

To investigate whether $\gamma \mathrm{H} 2 \mathrm{AX}$ amplification in the somatic ATR-dependent pathway is associated with transcriptional silencing, we performed double immunostaining of Pol II and $\gamma \mathrm{H} 2 \mathrm{AX}$ after $\mathrm{HU}$ treatment. As shown in Figure $6 \mathrm{E}$, sites of $\gamma \mathrm{H} 2 \mathrm{AX}$ accumulation after $\mathrm{HU}$ treatment were mutually exclusive from those of Pol II accumulation. In accord with our conclusion about the critical role of MDC1 in meiotic silencing, we establish that the common ATR-dependent pathway centered on MDC1 is associated with both meiotic silencing and transcriptional silencing following replicative stress.

\section{Discussion}

We demonstrate that MDC1 plays a critical role in chromosome-wide silencing of the sex chromosomes. However, 
A

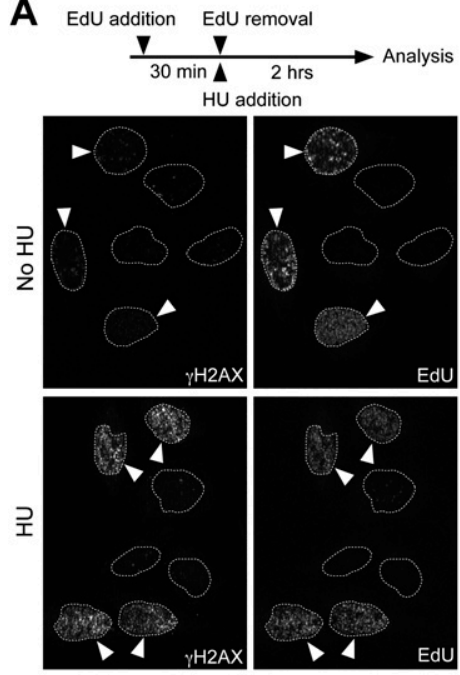

C

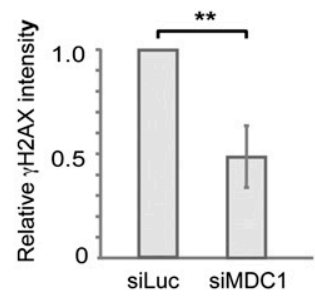

E

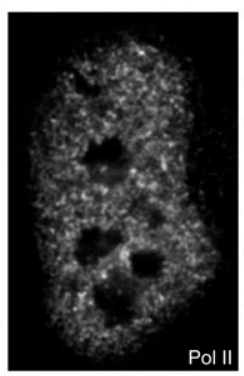

B
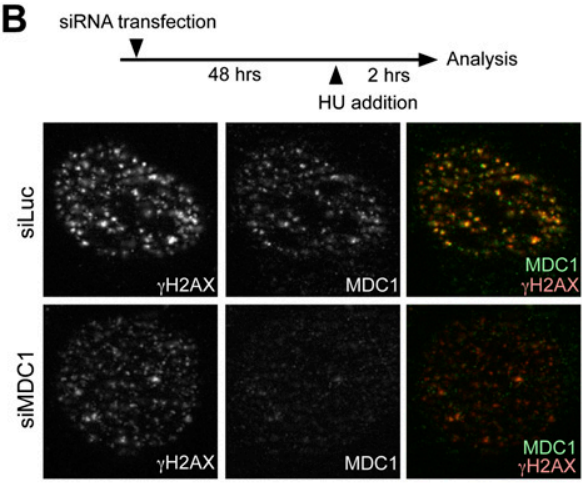

D

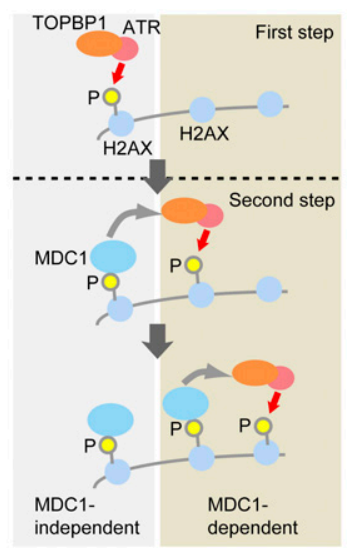

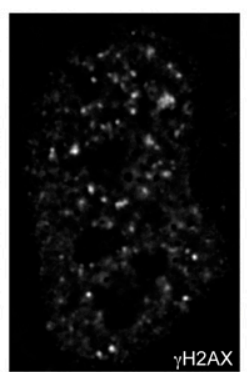

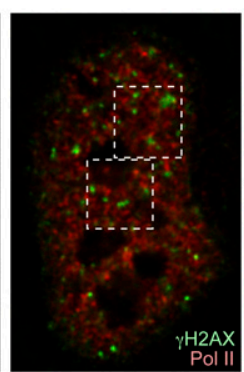

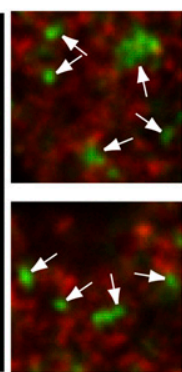

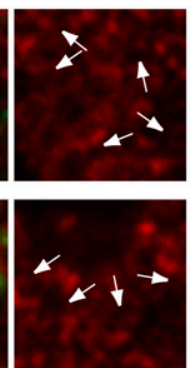

Figure 6. $\mathrm{MDCl}$ amplifies $\gamma \mathrm{H} 2 \mathrm{AX}$ signal after replicative stress in somatic cells. $(A)$ Replicative stress induction by $\mathrm{HU}$ and the appearance of $\gamma \mathrm{H} 2 \mathrm{AX}$ foci during $\mathrm{S}$ phase. U2OS cells were treated with $10 \mu \mathrm{M}$ EdU for $30 \mathrm{~min}$ prior to $1 \mathrm{mM} \mathrm{HU}$ treatment for $2 \mathrm{~h}$. Images are confocal images using Optiglid. (Arrowheads) S-phase cells. Dotted circles show nuclear regions. $(B) \gamma \mathrm{H} 2 \mathrm{AX}$ signal amplification is hampered by the knockdown of MDC1. U2OS cells were treated with siRNAs for $48 \mathrm{~h}$ prior to $1 \mathrm{mM} \mathrm{HU}$ treatment for $2 \mathrm{~h}$. siRNA for luciferase gene (siLuc) was used as a negative control. Images are confocal images using Optiglid. $(C)$ Quantification of $\gamma \mathrm{H} 2 \mathrm{AX}$ signal intensity after MDCl knockdown. More than 30 nuclei of three independent experiments were examined, quantified using the Image software, and normalized against the value of control siRNA (siLuc). $P$ was derived from an unpaired $t$-test. The error bar shows standard deviation. $(D)$ Model showing the role of $\mathrm{MDC} 1$ in $\gamma \mathrm{H} 2 \mathrm{AX}$ amplification. The first step is $\mathrm{MDCl}$-independent induction of $\gamma \mathrm{H} 2 \mathrm{AX}$. The second step is MDC1-dependent amplification of $\gamma \mathrm{H} 2 \mathrm{AX}$ signals in a feedback loop with TOPBP1 and ATR. MDC1 directs spreading of DDR factors to adjacent nucleosomes. (E) Foci of $\gamma \mathrm{H} 2 \mathrm{AX}$ and Pol II are mutually exclusive in U2OS cells after the 2-h HU treatment. Serial $Z$-sections were deconvolved and a representative $Z$-section is shown. Areas in dotted rectangles are magnified in the right panels. (Arrows) Sites of $\gamma \mathrm{H} 2 \mathrm{AX}$ foci. it is likely that $\mathrm{MDCl}$ is dispensable in meiotic recombination, which is a common event in both sexes, since $M d c 1^{-/-}$females are fertile (Lou et al. 2006) and we do not see defects in autosomal synapsis or formation of early recombination intermediates in males. We show that $M d c 1^{-1-}$ germ cells can partially retain early markers of meiotic silencing $(\gamma \mathrm{H} 2 \mathrm{AX}, \mathrm{ATR}$, and TOPBP1) only on the axes of sex chromosomes. However, $M d c 1^{-/-}$spermatocytes have defects in spreading these factors to the entire sex chromosome, in establishing the XY body, and in chromosome-wide gene silencing. A previous study suggests that MDC1 amplifies $\gamma \mathrm{H} 2 \mathrm{AX}$ by a feedback loop with the ATM kinase at the site of DSBs in somatic cells (Lou et al. 2006). Another study in somatic cells showed that $\gamma \mathrm{H} 2 \mathrm{AX}$ is dispensable for the initial recognition of DNA breaks but is required for amplification of DDR factors at DNA breaks (Celeste et al. 2003). Taken together, we propose that the initial $\gamma \mathrm{H} 2 \mathrm{AX}$ signal occurs at the unsynapsed axes of sex chromosomes in an MDC1-independent manner. MDC1 then mediates the spreading of the $\gamma \mathrm{H} 2 \mathrm{AX}$ signal over the chromosome-wide domain through a feedback loop with the ATR-TOPBP1 complex, thus leading to the recognition of the chromosome-wide domain and to XY body formation (Figs. 1G, 6D). In support of this model, a direct interaction between MDC1 and TOPBP1 has been identified in somatic cells following replicative stress (Wang et al. 2011). This finding strongly supports the possibility that MDC1 directly recruits the ATR-TOPBP1 complex to amplify the $\gamma \mathrm{H} 2 \mathrm{AX}$ signals in meiotic silencing (Fig. 6D), although other unidentified factors may also be involved in this process. The role of DDR factors in the recognition of the chromosomewide domain is further supported by our data showing that $\mathrm{XY}$ body markers do not localize to the chromosome-wide domain of the sex chromosomes in male $M d c 1^{-/-}$cells 
during meiosis (Fig. 4). Thus, a DDR pathway centered on $\mathrm{MDC} 1$ is the critical determinant of chromosome-wide cis regulation of the sex chromosomes in MSCI.

Although a previous study demonstrated that deletion of the H2AX gene abolishes MSCI (Fernandez-Capetillo et al. 2003), it is unclear whether $\gamma \mathrm{H} 2 \mathrm{AX}$ is the cue that signals MSCI. In somatic cells, MDC1 binds to $\gamma \mathrm{H} 2 \mathrm{AX}$ to exert its function (Stewart et al. 2003). In this study, defective MSCI in $M d c 1^{-/-}$mice provides compelling evidence that $\gamma \mathrm{H} 2 \mathrm{AX}$ is an essential signal for MSCI and $\mathrm{XY}$ body formation. Therefore, the current study provides the first genetic evidence that $\gamma \mathrm{H} 2 \mathrm{AX}$ and the associated DDR pathway are essential for MSCI.

DDR pathways mediate signaling downstream from DNA damage. Collapse of DDR pathways causes aberrant DNA repair, genomic instability, and predisposition to cancer (Andreassen and Niedernhofer 2009; Huen et al. 2010). We show that, in MSCI, recognition of the chromosome-wide domain by DDR factors takes place before the establishment of gene silencing and epigenetic modifications such as histone tail modifications. Surprisingly, our data suggest a common function for the DDR pathway and MDC1 in meiotic silencing and the response of somatic cells to DNA replication stress. It is well known that DNA replication stress stalls the replication fork in the mitotic $S$ phase and that an ATR-dependent signaling cascade plays a central role in the DDR at the stalled replication fork (Cimprich and Cortez 2008; Friedel et al. 2009). A recent study revealed that an ATM-dependent pathway is associated with transcriptional silencing at the site of DNA DSBs in somatic cells (Shanbhag et al. 2010). Taken together, these results suggest that transcriptional silencing is a common consequence of $\gamma \mathrm{H} 2 \mathrm{AX}$ amplification in response to replication stress and DSBs mediated by ATR and ATM, respectively.

Notably, our data reveal a novel mechanism of chromosome-wide regulation. We propose that MDC1 establishes chromosome-wide silencing via signal amplification of $\gamma \mathrm{H} 2 \mathrm{AX}$. Given that $\gamma \mathrm{H} 2 \mathrm{AX}$ foci are formed quite rapidly after induction of DNA damage in somatic cells, we suggest that the DDR pathway can provide an expeditious recognition of entire chromosomes during meiosis. These rapid kinetics during the initiation phase of MSCI are strikingly different from those of Xist-dependent X-chromosome inactivation in females. In both imprinted and random $\mathrm{X}$ inactivation, the noncoding RNA Xist gradually spreads and consequently establishes chromosome-wide genic silencing over several days (Okamoto et al. 2004; Chaumeil et al. 2006; Namekawa et al. 2010). The gradual establishment of female $\mathrm{X}$ inactivation may have enabled the regulation of several escape genes on a gene-by-gene basis, which eventually grew to be a relatively large number of escape genes in humans (such genes constitute $\sim 15 \%$ of genes on human X chromosomes) (Carrel and Willard 2005). On the other hand, the rapid kinetics of male MSCI could explain why MSCI results in an almost complete shutdown of the X-linked genes, with the exception of only a few X-linked coding genes and many X-linked microRNA (miRNA) genes (Namekawa et al. 2006; Song et al. 2009).
What is the raison d'etre for DDR pathway-based recognition of the chromosome-wide domain in MSCI? Importantly, $M d c 1^{-/-}$and $H 2 A X^{-/-}$mice exhibit complete arrest with no progression of spermatocytes to the later stages (Fernandez-Capetillo et al. 2003; Lou et al. 2006). It has been proposed that suppression of sex-linked genes is essential in meiotic progression, and that the MSCI defect activates the meiotic checkpoint that leads to apoptotic elimination of germ cells (Burgoyne et al. 2009). The rapid kinetics of MSCI would support this view in that expeditious silencing is critical in checkpoint suppression and meiotic progression. Furthermore, in the course of evolution, DDR pathway-based MSCI also confers long-term benefits that would justify selection in favor of MSCI. Several theories consider the evolutionary benefits of MSCI to be suppression of illegitimate recombination between unsynapsed sex chromosomes (McKee and Handel 1993), protection from invasion of transposons (Huynh and Lee 2005; Kelly and Aramayo 2007), and acting as a driving force of transgenerational epigenetic inheritance (Huynh and Lee 2005; Namekawa et al. 2006, 2007). Future challenges will be to test the evolutionary history of sex chromosome inactivation and dissect the molecular mechanisms downstream from $\gamma \mathrm{H} 2 \mathrm{AX}-\mathrm{MDC} 1$ signaling that confer transcriptional silencing and epigenetic memories on sex chromosomes.

\section{Materials and methods}

Mice

Mdc1, Spo11, and Rnf8 mutants were on C57BL/6 backgrounds. For slide preparation, mutants and littermate controls were processed at 20-60 d of age, post-partum. For the microarray analysis, juvenile testes were processed at post-partum day 16.5 . Embryos from $M d c 1^{-1-}$ females were obtained on embryonic day 17.5, after natural mating with $M d c 1$ heterozygous males.

\section{Spermatogenesis slide preparation}

Hypotonic treatment was performed as described (Peters et al. 1997). Slides to conserve the morphology of meiotic chromatin and relative three-dimensional nuclear structures in mouse testes were prepared as described (Namekawa et al. 2006; Namekawa and Lee 2011). To prepare paraffin blocks, testes were fixed with $4 \%$ paraformaldehyde in PBS, ethanol-dehydrated, and embedded in paraffin. Six-micron paraffin sections were prepared with a microtome (Leica) and deparaffinized prior to immunostaining.

\section{FISH and immunofluorescence}

Cot-1 RNA FISH was performed as described (Namekawa and Lee 2011). For immunofluorescence, slides were incubated in PBT (0.15\% BSA, $0.1 \%$ Tween 20 in PBS) for 60 min prior to overnight incubation at room temperature with the following antibodies: SCP3 (Novus), 1:100; Pol II CTD 8WG16 (Millipore), 1:200; H33meK27 (Millipore), 1:200; $\gamma \mathrm{H} 2 \mathrm{AX}$ (Millipore), 1:5000; ATR (Calbiochem), 1:400; TOPBP1 (generated by the Chen laboratory) (Yamane et al. 2002), 1:500; MDC1 (generated by the Nussenzweig laboratory), 1:500; SUMO-1 (Invitrogen), 1:400; XMR (gift from Denise Escalier), 1:500; macroH2A (Millipore), 1:200; ubiquitin conjugates (FK2, Enzo Life Sciences), 1:500; Ubi-H2A (Millipore), 1:200; H1t (gift from Mary Ann Handel), 1:500; SCP1 (Abcam), 1:1500; RAD51 (Calbiochem), 1:100; RPA1 (gift from James 
Ingles), 1:100; MLH1 (Santa Cruz Biotechnology), 1:100; RNF8 (gift from Xiaochun Yu), 1:100; PLZF (Calbiochem), 1:50; MRE11 (Novus), 1:200; and RAD50 (Novus), 1:200. Thereafter, slides were washed three times for $5 \mathrm{~min}$ in PBS plus $0.1 \%$ Tween 20, incubated with secondary antibodies (Invitrogen or Jackson ImmunoResearch) at 1:500 for $60 \mathrm{~min}$ in PBT, washed in PBS plus $0.1 \%$ Tween 20, and mounted in Vectashield with DAPI. The anti-BRCAl antibody was raised in rabbits using the mouse BRCAl fragment from 789 to 1141 amino acids (outsourced to Covance) and was used at 1:1500 dilution for immunostaining.

For double immunostaining using two primary antibodies from the same host species (mouse anti- $\gamma \mathrm{H} 2 \mathrm{AX}$ antibody and mouse anti-Pol II, clone $8 \mathrm{WG}$ ), we used Fab fragments as suggested by the manufacturer (Jackson ImmunoResearch). Briefly, we first performed immunostaining of $\gamma \mathrm{H} 2 \mathrm{AX}$ and detected with Fab goat anti-mouse IgG conjugated with DyLight488 (Jackson ImmunoResearch). After post-fixation in $4 \%$ paraformaldehyde in PBS, we performed a second round of immunostaining with anti-RNA polymerase antibody and detection with goat anti-mouse IgG conjugated with Alexa 555 (Invitrogen). For combined RNA FISH/immunostaining, we carried out immunofluorescent detection of proteins first, followed by RNA FISH. Details of FISH and immunofluorescence microscopy are described elsewhere (Namekawa and Lee 2011).

\section{Microarray analysis}

For microarray analysis, total RNAs from whole juvenile testes at $16.5 \mathrm{~d}$ of age were examined on Affymetrix Gene 1.0 ST arrays. Data were analyzed using Affymetrix Expression Console software for the calculation of expression levels, with each array normalized with the RMA algorithm. Temporal expression patterns observed in genes expressed at low levels are not reliable, so low-expression probes were eliminated, as we described previously (Namekawa et al. 2006). Approximately $40 \%$ of the genes in the mouse genome are not expressed in spermatogenesis (Namekawa et al. 2006), and thus $40 \%$ of low-expression probes were eliminated prior to the analysis. For the expression analysis, probes that do not specifically annotate the genome were eliminated from the analysis. Two biological replicates were analyzed and a representative data set was shown. Excel software was used to generate the figures.

\section{Cells; $H U$, siRNA, and EdU treatments; and fixation}

U2OS cells were purchased from American Type Culture Collection (ATCC; HTB-96) and cultured in McCoy's 5a medium (ATCC) supplemented with $10 \%$ fetal bovine serum, penicillin, and streptomycin. For the induction of replicative stress in U2OS cells, HU (Sigma-Aldrich) was added to the medium at a final concentration of $1 \mathrm{mM}$. After $2 \mathrm{~h}$ of incubation with HU, cells were examined.

siRNA duplexes for Luciferase and MDC1 were designed as described previously (Galanty et al. 2009) and were obtained from Thermo Scientific. U2OS cells were transfected with siRNAs using Dharmafect 1 (Thermo Scientific). HU treatment was performed at $48 \mathrm{~h}$ after siRNA transfection.

EdU was added to culture medium at a final concentration of 10 $\mu \mathrm{M}$ and cells were cultured for $30 \mathrm{~min}$. EdU was detected with Alexa Fluor 555 azide as suggested by the manufacturer (Invitrogen). After EdU staining, cells were further immunostained with anti- $\gamma \mathrm{H} 2 \mathrm{AX}$ antibodies. For the cytological analysis, cells were grown and processed on cover glasses. Cover glasses were rinsed in PBS and permeabilized with CSK buffer $(100 \mathrm{mM} \mathrm{NaCl}, 300$ $\mathrm{mM}$ sucrose, $10 \mathrm{mM}$ PIPES at $\mathrm{pH} 6.8,3 \mathrm{mM} \mathrm{MgCl}_{2}$ ) plus $0.5 \%$ Triton $\mathrm{X}-100$ for $6 \mathrm{~min}$ on ice, followed by fixation in $4 \%$ para- formaldehyde for $10 \mathrm{~min}$ at room temperature. For double staining of MDC1 and $\gamma \mathrm{H} 2 \mathrm{AX}$ in U2OS cells, cells were fixed with $-20^{\circ} \mathrm{C}$ cold methanol and kept for $>3 \mathrm{~h}$ at $-20^{\circ} \mathrm{C}$. Cells were then washed three times with PBS and incubated in PBS with $0.5 \%$ Triton X-100 for $10 \mathrm{~min}$ at room temperature. After washing with PBS, cells were incubated with the following primary antibodies: $\gamma \mathrm{H} 2 \mathrm{AX}$ (Millipore), 1:5000; and MDC1 (AbD Serotec), 1:500.

\section{Image acquisition and analysis}

All images were acquired with a TE2000-E microscope (Nikon) and a CoolSnapHQ camera (Photometrics). All image acquisition, including $Z$-sections and deconvolution, were performed using Phylum software (Improvision). For the analysis of U2OS cells, images were captured using an Optigrid confocal system, except for immunostaining with Pol II. For immunostaining of Pol II and Cot-1 RNA FISH, Z-sections were captured and deconvolved with Phylum software to eliminate any secondary signals from other $Z$-sections. A representative $Z$-section was shown. Adobe Photoshop was used for composing figures. For the analysis of meiosis, we analyzed a minimum of 50 nuclei of pachytene spermatocytes per staining. Particular stages of primary spermatocytes were determined by staining for SCP3.

\section{Acknowledgments}

We thank Mary Ann Handel, Xiaochun Yu, Denise Escalier, and James Ingles for providing antibodies; Yuya Ogawa, Ho-Su Sin, and Fumika N. Hamada for discussion and helpful comments regarding the manuscript; Marina A. Bellani, Katherine Minter Dykhouse, and Margarida Almeida Santos for help in transferring mice; S. Steven Potter and Shawn Smith for help with the microarray analysis; and Erin L. Adams for editing the manuscript. S.H.N. is deeply grateful to S.K. Dey and Jeannie T. Lee for their support of the initial stage of the Namekawa laboratory. This work was supported by the Developmental Fund and Trustee Grant at Cincinnati Children's Hospital Medical Center (to S.H.N.), the NCI (NIH) Intramural Research Program (A.N.), the NIDDK (NIH) Intramural Research Program (R.D.C.-O.), and NIH grants CA130996 (to Z.L.), CA092312 (to J.C.), and HL085587 (to P.R.A.).

\section{References}

Ahmed EA, van der Vaart A, Barten A, Kal HB, Chen J, Lou Z, Minter-Dykhouse K, Bartkova J, Bartek J, de Boer P, et al. 2007. Differences in DNA double strand breaks repair in male germ cell types: lessons learned from a differential expression of Mdc1 and 53BP1. DNA Repair (Amst) 6: 1243-1254.

Andreassen PR, Niedernhofer LJ. 2009. Fanconi anemia: a paradigm of discovering molecular pathways from patients. Mutat Res 668: 1-3.

Baarends WM, Wassenaar E, van der Laan R, Hoogerbrugge I, Sleddens-Linkels E, Hoeijmakers JH, de Boer P, Grootegoed JA. 2005. Silencing of unpaired chromatin and histone H2A ubiquitination in mammalian meiosis. Mol Cell Biol 25: 1041-1053.

Baker SM, Plug AW, Prolla TA, Bronner CE, Harris AC, Yao X, Christie DM, Monell C, Arnheim N, Bradley A, et al. 1996. Involvement of mouse Mlh1 in DNA mismatch repair and meiotic crossing over. Nat Genet 13: 336-342.

Barchi M, Mahadevaiah S, Di Giacomo M, Baudat F, de Rooij DG, Burgoyne PS, Jasin M, Keeney S. 2005. Surveillance of different recombination defects in mouse spermatocytes yields distinct responses despite elimination at an identical developmental stage. Mol Cell Biol 25: 7203-7215. 
Baudat F, Manova K, Yuen JP, Jasin M, Keeney S. 2000. Chromosome synapsis defects and sexually dimorphic meiotic progression in mice lacking Spo11. Mol Cell 6: 989998.

Bellani MA, Romanienko PJ, Cairatti DA, Camerini-Otero RD. 2005. SPO11 is required for sex-body formation, and Spo11 heterozygosity rescues the prophase arrest of Atm-/- spermatocytes. J Cell Sci 118: 3233-3245.

Burgoyne PS, Mahadevaiah SK, Turner JM. 2009. The consequences of asynapsis for mammalian meiosis. Nat Rev Genet 10: 207-216.

Carrel L, Willard HF. 2005. X-inactivation profile reveals extensive variability in $\mathrm{X}$-linked gene expression in females. Nature 434: 400-404.

Celeste A, Petersen S, Romanienko PJ, Fernandez-Capetillo O, Chen HT, Sedelnikova OA, Reina-San-Martin B, Coppola V, Meffre E, Difilippantonio MJ, et al. 2002. Genomic instability in mice lacking histone H2AX. Science 296: 922-927.

Celeste A, Fernandez-Capetillo O, Kruhlak MJ, Pilch DR, Staudt DW, Lee A, Bonner RF, Bonner WM, Nussenzweig A. 2003. Histone H2AX phosphorylation is dispensable for the initial recognition of DNA breaks. Nat Cell Biol 5: 675-679.

Chaumeil J, Le Baccon P, Wutz A, Heard E. 2006. A novel role for Xist RNA in the formation of a repressive nuclear compartment into which genes are recruited when silenced. Genes Dev 20: 2223-2237.

Chow JC, Heard E. 2010. Nuclear organization and dosage compensation. Cold Spring Harb Perspect Biol 2: a000604. doi: 10.1101/cshperspect.a000604.

Cimprich KA, Cortez D. 2008. ATR: an essential regulator of genome integrity. Nat Rev Mol Cell Biol 9: 616-627.

Eijpe M, Offenberg H, Goedecke W, Heyting C. 2000. Localisation of RAD50 and MRE11 in spermatocyte nuclei of mouse and rat. Chromosoma 109: 123-132.

Escalier D, Garchon HJ. 2000. XMR is associated with the asynapsed segments of sex chromosomes in the XY body of mouse primary spermatocytes. Chromosoma 109: 259265.

Fernandez-Capetillo O, Mahadevaiah SK, Celeste A, Romanienko PJ, Camerini-Otero RD, Bonner WM, Manova K, Burgoyne P, Nussenzweig A. 2003. H2AX is required for chromatin remodeling and inactivation of sex chromosomes in male mouse meiosis. Dev Cell 4: 497-508.

Friedel AM, Pike BL, Gasser SM. 2009. ATR/Mec1: coordinating fork stability and repair. Curr Opin Cell Biol 21: 237-244.

Furuta T, Takemura H, Liao ZY, Aune GJ, Redon C, Sedelnikova OA, Pilch DR, Rogakou EP, Celeste A, Chen HT, et al. 2003. Phosphorylation of histone H2AX and activation of Mre11, Rad50, and Nbs1 in response to replication-dependent DNA double-strand breaks induced by mammalian DNA topoisomerase I cleavage complexes. J Biol Chem 278: 20303-20312.

Galanty Y, Belotserkovskaya R, Coates J, Polo S, Miller KM, Jackson SP. 2009. Mammalian SUMO E3-ligases PIAS1 and PIAS4 promote responses to DNA double-strand breaks. Nature 462: 935-939.

Goldberg M, Stucki M, Falck J, D'Amours D, Rahman D, Pappin D, Bartek J, Jackson SP. 2003. MDC1 is required for the intraS-phase DNA damage checkpoint. Nature 421: 952-956.

Greaves IK, Rangasamy D, Devoy M, Marshall Graves JA, Tremethick DJ. 2006. The X and Y chromosomes assemble into H2A.Z, containing facultative heterochromatin, following meiosis. Mol Cell Biol 26: 5394-5405.

Hall LL, Byron M, Sakai K, Carrel L, Willard HF, Lawrence JB. 2002. An ectopic human XIST gene can induce chromosome inactivation in postdifferentiation human HT-1080 cells. Proc Natl Acad Sci 99: 8677-8682.
Hoyer-Fender S, Costanzi C, Pehrson JR. 2000. Histone macroH2A1.2 is concentrated in the XY-body by the early pachytene stage of spermatogenesis. Exp Cell Res 258: 254-260.

Huen MS, Grant R, Manke I, Minn K, Yu X, Yaffe MB, Chen J. 2007. RNF8 transduces the DNA-damage signal via histone ubiquitylation and checkpoint protein assembly. Cell 131: 901-914.

Huen MS, Sy SM, Chen J. 2010. BRCA1 and its toolbox for the maintenance of genome integrity. Nat Rev Mol Cell Biol 11: 138-148.

Huynh KD, Lee JT. 2005. X-chromosome inactivation: a hypothesis linking ontogeny and phylogeny. Nat Rev Genet 6: 410-418.

Inagaki A, Schoenmakers S, Baarends WM. 2010. DNA double strand break repair, chromosome synapsis and transcriptional silencing in meiosis. Epigenetics 5: 255-266.

Inselman A, Eaker S, Handel MA. 2003. Temporal expression of cell cycle-related proteins during spermatogenesis: establishing a timeline for onset of the meiotic divisions. Cytogenet Genome Res 103: 277-284.

Kelly WG, Aramayo R. 2007. Meiotic silencing and the epigenetics of sex. Chromosome Res 15: 633-651.

Kolas NK, Chapman JR, Nakada S, Ylanko J, Chahwan R, Sweeney FD, Panier S, Mendez M, Wildenhain J, Thomson TM, et al. 2007. Orchestration of the DNA-damage response by the RNF8 ubiquitin ligase. Science 318: 1637-1640.

Lee JT. 2010. The X as model for RNA's niche in epigenomic regulation. Cold Spring Harb Perspect Biol 2: a003749. doi: 10.1101/cshperspect.a003749.

Lee AC, Fernandez-Capetillo O, Pisupati V, Jackson SP, Nussenzweig A. 2005. Specific association of mouse MDC1/ NFBD1 with NBS1 at sites of DNA-damage. Cell Cycle 4: 177182.

Lou Z, Minter-Dykhouse K, Wu X, Chen J. 2003. MDC1 is coupled to activated CHK2 in mammalian DNA damage response pathways. Nature 421: 957-961.

Lou Z, Minter-Dykhouse K, Franco S, Gostissa M, Rivera MA, Celeste A, Manis JP, van Deursen J, Nussenzweig A, Paull TT, et al. 2006. MDC1 maintains genomic stability by participating in the amplification of ATM-dependent DNA damage signals. Mol Cell 21: 187-200.

Lu LY, Wu J, Ye L, Gavrilina GB, Saunders TL, Yu X. 2010. RNF8-dependent histone modifications regulate nucleosome removal during spermatogenesis. Dev Cell 18: 371-384.

Mahadevaiah SK, Turner JM, Baudat F, Rogakou EP, de Boer P, Blanco-Rodriguez J, Jasin M, Keeney S, Bonner WM, Burgoyne PS. 2001. Recombinational DNA double-strand breaks in mice precede synapsis. Nat Genet 27: 271-276.

Mahadevaiah SK, Bourc'his D, de Rooij DG, Bestor TH, Turner JM, Burgoyne PS. 2008. Extensive meiotic asynapsis in mice antagonises meiotic silencing of unsynapsed chromatin and consequently disrupts meiotic sex chromosome inactivation. J Cell Biol 182: 263-276.

Mailand N, Bekker-Jensen S, Faustrup H, Melander F, Bartek J, Lukas C, Lukas J. 2007. RNF8 ubiquitylates histones at DNA double-strand breaks and promotes assembly of repair proteins. Cell 131: 887-900.

McCarrey JR, Watson C, Atencio J, Ostermeier GC, Marahrens Y, Jaenisch R, Krawetz SA. 2002. X-chromosome inactivation during spermatogenesis is regulated by an Xist/Tsix-independent mechanism in the mouse. Genesis 34: 257-266.

McKee BD, Handel MA. 1993. Sex chromosomes, recombination, and chromatin conformation. Chromosoma 102: 71-80.

Moens PB, Tarsounas M, Morita T, Habu T, Rottinghaus ST, Freire R, Jackson SP, Barlow C, Wynshaw-Boris A. 1999. The association of ATR protein with mouse meiotic chromosome cores. Chromosoma 108: 95-102. 
Namekawa SH, Lee JT. 2009. XY and ZW: is meiotic sex chromosome inactivation the rule in evolution? PLoS Genet 5: e1000493. doi: 10.1371/journal.pgen.1000493.

Namekawa SH, Lee JT. 2011. Detection of nascent RNA, singlecopy DNA and protein localization by immunoFISH in murine germ cells and pre-implantation embryos. Nat Protoc 6: 270-284.

Namekawa SH, Park PJ, Zhang LF, Shima JE, McCarrey JR, Griswold MD, Lee JT. 2006. Postmeiotic sex chromatin in the male germline of mice. Curr Biol 16: 660-667.

Namekawa SH, VandeBerg JL, McCarrey JR, Lee JT. 2007. Sex chromosome silencing in the marsupial male germ line. Proc Natl Acad Sci 104: 9730-9735.

Namekawa SH, Payer B, Huynh KD, Jaenisch R, Lee JT. 2010. Two-step imprinted $\mathrm{X}$ inactivation: repeat versus genic silencing in the mouse. Mol Cell Biol 30: 3187-3205.

Okamoto I, Otte AP, Allis CD, Reinberg D, Heard E. 2004. Epigenetic dynamics of imprinted $\mathrm{X}$ inactivation during early mouse development. Science 303: 644-649.

Perera D, Perez-Hidalgo L, Moens PB, Reini K, Lakin N, Syvaoja JE, San-Segundo PA, Freire R. 2004. TopBP1 and ATR colocalization at meiotic chromosomes: role of TopBP1/ Cut5 in the meiotic recombination checkpoint. Mol Biol Cell 15: 1568-1579.

Peters AH, Plug AW, van Vugt MJ, de Boer P. 1997. A dryingdown technique for the spreading of mammalian meiocytes from the male and female germline. Chromosome Res 5: 66-68.

Plug AW, Peters AH, Keegan KS, Hoekstra MF, de Boer P, Ashley T. 1998. Changes in protein composition of meiotic nodules during mammalian meiosis. J Cell Sci 111: 413-423.

Reini K, Uitto L, Perera D, Moens PB, Freire R, Syvaoja JE. 2004. TopBP1 localises to centrosomes in mitosis and to chromosome cores in meiosis. Chromosoma 112: 323-330.

Rogers RS, Inselman A, Handel MA, Matunis MJ. 2004. SUMO modified proteins localize to the XY body of pachytene spermatocytes. Chromosoma 113: 233-243.

Romanienko PJ, Camerini-Otero RD. 2000. The mouse Spol1 gene is required for meiotic chromosome synapsis. Mol Cell 6: 975-987.

Santos MA, Huen MS, Jankovic M, Chen HT, Lopez-Contreras AJ, Klein IA, Wong N, Barbancho JL, Fernandez-Capetillo O, Nussenzweig MC, et al. 2010. Class switching and meiotic defects in mice lacking the E3 ubiquitin ligase RNF8. I Exp Med 207: 973-981.

Scully R, Chen J, Plug A, Xiao Y, Weaver D, Feunteun J, Ashley T, Livingston DM. 1997. Association of BRCA1 with Rad51 in mitotic and meiotic cells. Cell 88: 265-275.

Shanbhag NM, Rafalska-Metcalf IU, Balane-Bolivar C, Janicki SM, Greenberg RA. 2010. ATM-dependent chromatin changes silence transcription in cis to DNA double-strand breaks. Cell 141: 970-981.

Song R, Ro S, Michaels JD, Park C, McCarrey JR, Yan W. 2009. Many X-linked microRNAs escape meiotic sex chromosome inactivation. Nat Genet 41: 488-493.

Stewart GS, Wang B, Bignell CR, Taylor AM, Elledge SJ. 2003. MDC1 is a mediator of the mammalian DNA damage checkpoint. Nature 421: 961-966.

Tarsounas M, Morita T, Pearlman RE, Moens PB. 1999. RAD51 and DMC1 form mixed complexes associated with mouse meiotic chromosome cores and synaptonemal complexes. J Cell Biol 147: 207-220.

Turner JM. 2007. Meiotic sex chromosome inactivation. Development 134: 1823-1831.

Turner JM, Mahadevaiah SK, Elliott DJ, Garchon HJ, Pehrson JR, Jaenisch R, Burgoyne PS. 2002. Meiotic sex chromosome inactivation in male mice with targeted disruptions of Xist. J Cell Sci 115: 4097-4105.

Turner JM, Aprelikova O, Xu X, Wang R, Kim S, Chandramouli GV, Barrett JC, Burgoyne PS, Deng CX. 2004. BRCA1, histone H2AX phosphorylation, and male meiotic sex chromosome inactivation. Curr Biol 14: 2135-2142.

Turner JM, Mahadevaiah SK, Fernandez-Capetillo O, Nussenzweig A, Xu X, Deng CX, Burgoyne PS. 2005. Silencing of unsynapsed meiotic chromosomes in the mouse. Nat Genet 37: 41-47.

Turner JM, Mahadevaiah SK, Ellis PJ, Mitchell MJ, Burgoyne PS. 2006. Pachytene asynapsis drives meiotic sex chromosome inactivation and leads to substantial postmeiotic repression in spermatids. Dev Cell 10: 521-529.

van der Heijden GW, Derijck AA, Posfai E, Giele M, Pelczar P, Ramos L, Wansink DG, van der Vlag J, Peters AH, de Boer P. 2007. Chromosome-wide nucleosome replacement and H3.3 incorporation during mammalian meiotic sex chromosome inactivation. Nat Genet 39: 251-258.

Vigodner M. 2009. Sumoylation precedes accumulation of phosphorylated $\mathrm{H} 2 \mathrm{AX}$ on sex chromosomes during their meiotic inactivation. Chromosome Res 17: 37-45.

Wang J, Gong Z, Chen J. 2011. MDC1 collaborates with TopBP1 in DNA replication checkpoint control. I Cell Biol doi: 10.1083/jcb.201010026.

Yamane K, Wu X, Chen J. 2002. A DNA damage-regulated BRCT-containing protein, TopBP1, is required for cell survival. Mol Cell Biol 22: 555-566.

Yan W, McCarrey JR. 2009. Sex chromosome inactivation in the male. Epigenetics 4: 452-456. 


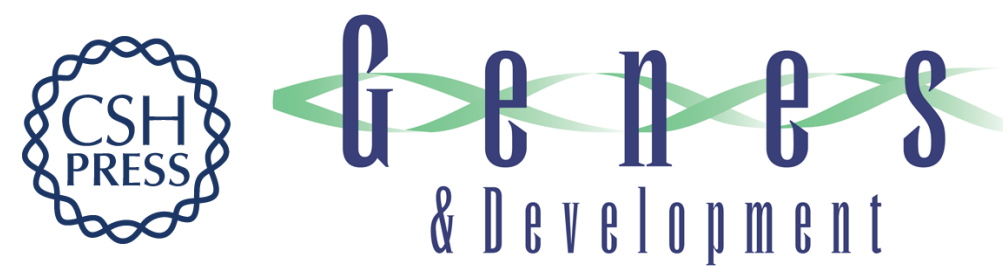

\section{MDC1 directs chromosome-wide silencing of the sex chromosomes in male germ cells}

Yosuke Ichijima, Misako Ichijima, Zhenkun Lou, et al.

Genes Dev. 2011, 25:

Access the most recent version at doi:10.1101/gad.2030811

\section{Supplemental http://genesdev.cshlp.org/content/suppl/2011/04/25/25.9.959.DC1 Material}

References This article cites 69 articles, 22 of which can be accessed free at: http://genesdev.cshlp.org/content/25/9/959.full.html\#ref-list-1

\section{License}

Email Alerting

Receive free email alerts when new articles cite this article - sign up in the box at the top Service 